than in those without (0.63 IQR (0.55-0.77) mm versus $0.51(0.44-0.55) \mathrm{mm}$, $\mathrm{P}=0.02$ ) (Figure $1 \mathrm{~A}$ ). IMT was neither correlated with duration of APS nor with antibody titers.

Variables associated with IMT were studied on uni- and multivariate analysis (Table 1). On univariate analysis, age, aCL positivity and stroke were significantly associated with IMT and were included in the multivariate analysis. On multivariate analysis, there was a positive, independent and significant association between IMT and stroke ( $\mathrm{P}=0.047)$ and between IMT and age $(\mathrm{P}=0.024)$. aCL positivity was not associated with IMT on multivariate analysis (Figure 1B).

Conclusion: Intima-media thickness is independently associated with stroke in primary antiphospholipid antibody syndrome.

REFERENCES:

[1] Medina G. Increased carotid artery intima-media thickness may be associated with stroke in primary antiphospholipid syndrome. Ann Rheum Dis. 2003;62(7):607-610. doi:10.1136/ard.62.7.607

Characters from table content including title and footnotes.

Table 1. Predictors of intima-media thickness on uni- and multivariate analysis.

\begin{tabular}{|c|c|c|c|c|}
\hline & \multicolumn{2}{|c|}{ Univariate analysis } & \multicolumn{2}{|c|}{$\begin{array}{c}\text { Multivariate } \\
\text { analysis* }\end{array}$} \\
\hline & $\beta$ & $P$-value & $\beta$ & $P$-value \\
\hline Age (years) & 0.006 & $<0.001$ & 0.004 & 0.024 \\
\hline Female sex & -0.102 & 0.18 & & \\
\hline APS duration (years) & 0.0004 & 0.31 & & \\
\hline Smoker & -0.05 & 0.61 & & \\
\hline Overweight & 0.066 & 0.39 & & \\
\hline Arterial hypertension & 0.047 & 0.48 & & \\
\hline Hypercholesterolemia & 0.05429 & 0.412 & & \\
\hline Anti-cardiolipin antibodies & 0.12 & 0.05 & 0.084 & 0.076 \\
\hline Anti-phospholipid antibodies & 0.054 & 0.44 & & \\
\hline Anti- $\beta 2$ GP1 & 0.094 & 0.15 & & \\
\hline Lupus-anticoagulant & 0.044 & 0.49 & & \\
\hline Anticoagulation & -0.07 & 0.31 & & \\
\hline Stroke & 0.139 & 0.02 & 0.099 & 0.047 \\
\hline
\end{tabular}

$\beta$ Linear regression coefficientsAPS Antiphospholipid antibody syndrome ${ }^{*}$ Variables with a $P$-value $<0.1$ on univariate analysis were included

A

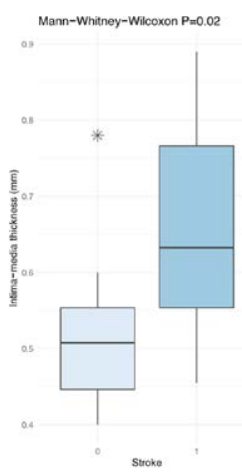

Figure 1. A.Intima-media thickness according to stroke statusB.Multivariate analysis forest-plot of intima-media thickness predictorsOR Odds-ratioaCL anti-cardiolipin antibodies

Disclosure of Interests: None declared

DOI: 10.1136/annrheumdis-2021-eular.2661

\section{AB0324 ALLERGIC DISORDERS AND DRUG ALLERGIES IN PRIMARY SJÖGREN'S SYNDROME AND RHEUMATOID ARTHRITIS}

M. Higashida-Konishi ${ }^{1}$, K. Izumi ${ }^{1,2}$, S. Hama ${ }^{1}$, H. Takei ${ }^{1}$, H. Oshima ${ }^{1}$, Y. Okano ${ }^{1}$. ${ }^{1}$ National Hospital Organization Tokyo Medical Center, Department of Connective Tissue Diseases, Tokyo, Japan; ${ }^{2}$ Keio University School of Medicine, Division of Rheumatology, Department of Internal Medicine, Tokyo, Japan

Background: Allergic disorders have been reported in a variety of rheumatic diseases. A high prevalence of allergic disorders was found in patients with Sjoegren's syndrome [1]. Nevertheless, it was not clear what is a risk factor for allergic disorders and drug allergies in patients with primary Sjögren's syndrome (pSS). Drug allergies may lead to delayed treatment and unnecessary clinical tests.
Objectives: The primary aim of this study was to compare the prevalence of allergic disorders and drug allergies in patients with pSS and rheumatoid arthritis (RA). The secondary aim was to compare the clinical features with and without drug allergies in patients with pSS.

Methods: We retrospectively examined consecutive patients diagnosed with pSS or RA in our hospital from 2010 to 2020 . The patients with SS met the criteria of the 1999 revised Japanese Ministry of Health criteria[2]. We included patients with pSS without RA or other rheumatic diseases. The patients with RA met the EULAR/ACR 2010 criteria. We included patients with RA without other rheumatic diseases.

The first analysis was performed on six types of allergic reactions: (1) food allergy (exanthema, angioedema and anaphylaxis after foods exposure), (2) drug allergy (exanthema, angioedema and anaphylaxis after drug exposure), (3) allergic contact dermatitis such as metals, alcohol swab, and other cosmetics, (4) seasona allergic rhinitis and/or allergic conjunctivitis, and allergic rhinitis and/or allergic conjunctivitis associated with house dust, (5) asthma, and (6) atopic dermatitis. The secondary analysis was performed on patient baseline laboratory data at diagnosis of pSS and RA patients with or without drug allergies.

Results: In the first analysis, 292 patients with pSS and 413 patients with RA were enrolled (Table 1). The mean ages (pSS, RA) were $57.3 \pm 15.8,66.0 \pm 14.6$ years old. Females were $94.2 \%, 78.2 \%$. The mean observation period was $82.7 \pm 70.8,65.6 \pm 37.0$ months. $54.8 \%$ of pSS patients and $34.9 \%$ of RA patients presented at least one type of allergic disorders or drug allergies. These included food allergy, drug allergy, allergic rhinitis/conjunctivitis, asthma, and atopic dermatitis. Allergic disorders and drug allergies were more frequent in patients with pSS.

In the second analysis, 77 patients with drug allergies and 215 patients without drug allergies were enrolled. The mean ages with drug allergies and without drug allergies were $56.0 \pm 15.8$ and $57.8 \pm 15.8$ years old, respectively; females were $96.1 \%$ and $93.5 \%$; the mean observation period was $90.9 \pm 72.4$ and $79.8 \pm 70.2$ months. The pSS patients with drug allergies had higher levels of Immunoglobulin G (IgG) $(2028 \pm 1409 \mathrm{mg} / \mathrm{dL}, 1726 \pm 587 \mathrm{mg} / \mathrm{dL}: \mathrm{p}=0.01)$, higher levels of eosinophils $(220 \pm 247 / \mu \mathrm{L}, 126 \pm 112 / \mu \mathrm{L}$ : $\mathrm{p}<0.019)$, and higher positivity rate of anti-Sjögren's-syndrome-related antigen A autoantibody (anti-SSA antibody) than those without drug allergies $(89.6 \%, 79.7 \%: p=0.06)$.

Conclusion: Patients with pSS had a higher prevalence of allergic disorders and drug allergies than patients with RA. Among patients with pSS, patients with drug allergies had higher levels of IgG, higher levels of eosinophils, and higher positivity rate of anti-SSA antibody than those without drug allergies.

Table 1. Allergic Disorders and Drug Allergies in pSS and RA

\begin{tabular}{lccc}
\hline & pSS $(\mathrm{n}=292)$ & $\mathrm{RA}(\mathrm{n}=413)$ & $\mathrm{P}$ \\
\hline at least one type of allergy, $\mathrm{n}(\%)$ & $160(54.8)$ & $144(34.9)$ & $<0.01$ \\
food allergy, $\mathrm{n}(\%)$ & $35(12.0)$ & $27(6.7)$ & 0.02 \\
drug allergy, $\mathrm{n}(\%)$ & $76(26.1)$ & $69(16.7)$ & $<0.01$ \\
allergic contact dermatitis, $\mathrm{n}(\%)$ & $10(3.4)$ & $19(4.6)$ & 0.6 \\
allergic rhinitis and/or conjunctivitis, $\mathrm{n}(\%)$ & $99(33.9)$ & $35(8.5)$ & $<0.01$ \\
asthma, $\mathrm{n}(\%)$ & $29(9.9)$ & $25(6.1)$ & 0.06 \\
atopic dermatitis, $\mathrm{n}(\%)$ & $15(5.1)$ & $0(0)$ & $<0.01$ \\
\hline
\end{tabular}

\section{REFERENCES:}

[1] Hama et al. Clinical features of patients with Sjoegren syndrome associated with adult onset Still's disease. Japan College of Rheumatology Annual Congress 2020.

[2] Fujibayashi et al. Revised Japanese criteria for Sjögren's syndrome (1999): availability and validity. Mod Rheumatol. 2004; 14: 425-34

Disclosure of Interests: None declared

DOI: 10.1136/annrheumdis-2021-eular.2704

\section{AB0325 2 FREQUENCY OF ATHEROMATOUS PLAQUES IN CAROTID ARTERIES BY DOPPLER IN PATIENTS WITH SYSTEMIC LUPUS ERYTHEMATOSUS, SANTO DOMINGO, DOMINICAN REPUBLIC}

J. Santana Peralta ${ }^{1}$, T. Polanco Mora ${ }^{2}$, A. Cornelio ${ }^{1}$, Y. Cruz ${ }^{1}$, E. Rodriguez Bautista ${ }^{1}$, T. Valdez ${ }^{1}$, R. Muñoz ${ }^{1}$, A. Feriz ${ }^{1}{ }^{1}$ Hospital Docente Padre Billini, Rheumatology, Santo Domingo, Dominican Republic; ${ }^{2}$ Hospital Docente Padre Billini, Rheumatology, Santo DOMINGO, Dominican Republic

Background: Systemic lupus erythematosus (SLE) is a multisystemic autoim mune disease. ${ }^{1}$ Atherosclerosis is considered an alteration of the arteries by the abnormal deposit of lipids and fibrous tissue. ${ }^{2}$ Cardiovascular disease is one of the leading causes of morbidity and mortality, especially due to its precocity, which occurs in women during childbearing age, is associated with a higher prev alence of cardiovascular disease (CVD), due to accelerated atherosclerosis ${ }^{3,4,5}$. Patients with rheumatic diseases have an increased cardiovascular risk due to 